\title{
Carreiras públicas em uma ordem democrática: entre os modelos burocrático e gerencial
}

\section{Introdução}

Na temática da reforma da Administração Pública, importante questão refere-se ao modelo de carreira mais compatível com as novas funções do Estado, nesta era de economia globalizada e de maiores exigências de eficiência e flexibilidade na gestão dos aparatos governamentais. A maioria dos estudos tem afirmado que o modelo burocrático, freqüentemente identificado também como weberiano, não é mais adequado e que, para se alcançarem eficiência, agilidade e flexibilidade na gestão pública, faz-se necessária a substituição da administração burocrática, vista como excessivamente formalista, autocentrada e ineficiente, por novo modelo de administração, definido como gerencial ${ }^{1}$ (Presidência da República, 1995; Bresser Pereira, 2001; CLAD, 2000; Cunill, 2000). Sustenta-se, por exemplo, que o funcionamento da máquina administrativa estatal com base em procedimentos de recrutamento e carreira excessivamente formais e em critérios rígidos de controle e avaliação do desempenho dos funcionários públicos não mais atende à necessidade de prestação eficiente dos serviços públicos, demandados crescentemente pela população.

Procuramos discutir aqui essas idéias, mostrando que elas são verdadeiras apenas parcialmente. O primeiro equívoco cometido pelos que defendem a substituição do modelo burocrático é não levar em conta que a realização histórico-concreta deste tipo ideal, na acepção metodológica de Weber, não tem sido, às vezes, bem-sucedida e, muitas vezes, nem sequer concretizada, especialmente em países como o Brasil, em que o patrimonialismo, o clientelismo e outras formas de dominação tradicional não foram completamente superados. Ao contrário, tais formas tradicionais

Clovis Bueno de Azevedo e Maria Rita Loureiro são professores da Escola de Administração de Empresas de São Paulo da Fundação Getúlio Vargas.

Contato: cazevedo@ fgvsp.br mrloureiro@ yahoo.com 
têm sido sempre reatualizadas, dadas as características do presidencialismo de coalizão, que requer, como condição de governabilidade, negociações continuadas entre Executivo e Legislativo, envolvendo trocas de cargos na administração por apoio do Congresso à agenda do governo (Nunes, 1997; Mainwaring e Shugart, 1997; Loureiro e Abrucio, 1999; Palermo, 2001). Sob esse ponto de vista, portanto, a questão não é abandonar, ou não, o modelo burocrático, mas, sim, refletir acerca da necessidade e possibilidade de sua reconstrução.

O núcleo de nosso argumento é que a administração burocrática é o modelo mais compatível com uma ordem política republicana e democrática, na qual o primado do interesse público sobre o particular e a igualdade de todos os cidadãos constituem idéias centrais. Legalidade, impessoalidade, regras formais e universais são princípios que normativamente devem orientar não só a ação dos funcionários quando executam as funções do Estado, mas igualmente a estruturação das carreiras públicas, ou seja, os processos de recrutamento, promoção, avaliação e controle dos atos e omissões dos membros do aparato estatal. Em outras palavras, o modelo burocrático de administração contém os princípios fundamentais do Estado de Direito, indispensáveis ao ordenamento democrático dos aparatos administrativos.

Todavia, o modelo burocrático não só pode e precisa ser flexibilizado, mas igualmente deve ser aperfeiçoado em seus mecanismos de controle, até como condição para sua manutenção eficaz nos governos democráticos contemporâneos. Isso por duas razões principais:

a) Diferentemente da idealização weberiana, os burocratas, nas democracias contemporâneas, não apenas administram, mas participam junto com os políticos do processo de tomada de decisão, configurando-se também como policymakers (Aberbach, Putnam e Rockman, 1981)2. Tal mudança crucial no papel atribuído classicamente a esses dois atores políticos requer a responsabilização dos burocratas não apenas administrativa e hierarquicamente, como pensava Weber, mas também politicamente.

b) A flexibilização do modelo burocrático implica a adoção - até mesmo, se necessário, a invenção - de formas mais adequadas, ágeis e criativas, para realizar os princípios de boa governança democrática, mas não a sua substituição ${ }^{3}$. Entendemos, portanto, flexibilização tal como no sentido definido por Sennet (1996), ou seja, como aperfeiçoamento e não ruptura. Segundo Sennet, a flexibilização corresponde à sua gravitação em torno de um eixo e não ao seu abandono, logo não implica o enfraquecimento, mas, sim, o reforço desse mesmo eixo. De fato, estruturas rígidas se quebram, estruturas flexíveis são mais perenes e resistentes. Assim sendo, não há substituição, mas aprimoramento; não há negação dos princípios, mas, a rigor e ao contrário, o seu reforço ou fortalecimento. 
No texto que se segue, retomamos, para reforço de nossa argumentação, algumas idéias centrais da obra de Weber a respeito das relações entre administração burocrática e democracia. Em seguida, examinamos, de forma crítica, as propostas de criação de modelo de administração gerencial no Brasil, por meio do Plano Diretor da Reforma do Estado. Nessa parte procuramos reinterpretar o texto, a fim de mostrar que é possível chegar a uma conclusão inversa à que está ali proposta. Nas conclusões, reafirmamos a idéia de que não se trata de promover rupturas ou de substituir um modelo pelo outro, mas de melhor aplicar os mesmos princípios fundamentais da administração do Estado em uma ordem democrática.

\section{Weber, política, burocracia e carreiras públicas em uma ordem democrática}

Retomando, ainda que brevemente, os estudos clássicos de Weber sobre o tema, cabe relembrar que o modelo burocrático de organização do aparato administrativo é típico do Estado moderno, ou seja, da estrutura de poder que legitima seu monopólio dos meios de coerção por meio de normas legais. Assim, na dominação de tipo burocrático ou racional-legal, as relações entre dominantes e dominados estabelecem-se por intermédio de regras abstratas, que só são aceitas se o mandante não ultrapassar os limites estabelecidos pela ordem jurídica, sendo tal obediência devida apenas dentro dos limites dessas regras. As relações de autoridade ordenam-se de forma hierárquica e são definidas por critérios de competência, com clara distinção entre o cargo e a pessoa que exerce a dominação. Os funcionários da organização burocrática são profissionais especializados, recrutados por mérito, tendem a exercer sua ocupação de forma continuada no tempo, pautam suas condutas pelas normas legais previamente estabelecidas, não se submetem à vontade pessoal do chefe superior, nem tampouco exercem poder discricionário sobre seus subalternos ${ }^{4}$. Portanto, as regras abstratas, universais e impessoais da dominação burocrática exprimem a natureza pública do poder no Estado de Direito.

Embora igualmente sabido, cabe relembrar também que Weber construiu o modelo burocrático, acentuando deliberadamente seus traços - com claro propósito metodológico - para diferenciá-lo do modelo de dominação patrimonial. Neste, os funcionários, clientes de quem detém o poder, são recompensados em dinheiro, bens ou outros benefícios. No modelo patrimonial, as funções administrativas não são atribuídas em função de critérios de competência, nem tampouco organizadas em hierarquias racionais, mas distribuídas pelo arbítrio do dominante, e tendem a não ser exercidas de forma continuada no tempo. Ao contrário do modelo 
burocrático, não há distinção entre pessoa e cargo, e o aparato administrativo é considerado parte do patrimônio pessoal do mandante .

É importante realçar os elementos da construção do tipo ideal weberiano de burocracia, porque, diante do funcionamento - sempre imperfeito e muitas vezes deformado - das administrações burocráticas no mundo real, costuma-se descaracterizar a burocracia como princípio organizatório das relações de mando. $\mathrm{Na}$ verdade, Weber não apenas enuncia as características do domínio legal-burocrático, mas constrói também uma análise histórica do processo de burocratização, sublinhando os efeitos da emergência da burocracia moderna (Bobbio, Matteucci e Pasquino,1995). Assim, ele aponta a concentração dos meios de administração e gestão nas mãos dos detentores do poder, fenômeno presente em todas as grandes organizações, no Estado, em empresas privadas, universidades, partidos, etc. Destaca também o nivelamento das diferenças sociais, que resulta do exercício da autoridade, segundo regras abstratas e iguais para todos, e da exclusão de considerações pessoais no recrutamento dos funcionários. E, sobretudo, considera os potenciais conflitos que decorrem da dominação racional-legal ou burocrática, destacando-se, em particular, o dilema entre burocracia e democracia. Esse dilema reside no fato de que a burocracia, embora seja condição necessária para o Estado de Direito e para uma ordem democrática, pode também, paradoxalmente, vir a constituir ameaça a si mesma.

De um lado, a autonomia da burocracia diante dos governantes do momento, que passam pelo Estado a cada ciclo eleitoral, é fundamental para a preservação da democracia, porque previne os riscos do oportunismo partidário, da manipulação eleitoral ou mesmo do uso clientelista da máquina pública. De outro, a existência de burocracia poderosa e independente coloca em risco a própria democracia, na medida em que o poder dos burocratas, que não têm responsabilidade política perante os eleitores, pode se impor sobre o poder originário das urnas (Etzioni-Halevy, 1983; Reis, 1989). Tendo plena consciência desse dilema e dos riscos aí sempre presentes, Weber já apontava "inseparável complementaridade" entre políticos e burocratas no mundo moderno, a despeito do caráter intrinsecamente tenso das relações entre política e burocracia (Weber, 1993; Cohn, 1993).

A partir dessas considerações analíticas e normativas com relação ao papel da burocracia em uma ordem democrática é que analisaremos a proposta de reorganização das carreiras públicas no Brasil recente. 
Carreiras e reforma da Administração

Pública no Brasil hoje: quais os desafios?

Quais são os desafios presentes para a Administração Pública brasileira, tendo em vista as contradições e ambigüidades dos princípios que têm orientado as atuais reformas (Azevedo, 2001) e ainda levando-se em conta que a questão, hoje, no serviço público não é mais a redução dos contingentes ou os gastos com pessoal (mesmo considerando que, do ponto de vista fiscal, o problema central é o pagamento dos inativos que comprometem a folha dos ativos), e, sim, a questão da eficiência na prestação dos serviços e de accountability, ou seja, da responsabilização da burocracia por seus atos ou omissões? Seria efetivamente necessário, para obter eficiência e qualidade, abandonar o modelo burocrático e substituí-lo pelo gerencial ${ }^{5}$ ?

Procuraremos agora responder a essa questão, analisando o Plano Diretor da Reforma do Estado, documento publicado em 1995 pelo governo federal brasileiro, por meio do qual divulgou-se ao país a proposta oficial de reforma de nossa Administração Pública.

A posição a respeito de qual seja a proposta adequada para a reforma da Administração Pública em nosso país expressa no citado Plano Diretor consiste também na afirmação da necessidade de substituir o modelo burocrático, tido como ineficiente e autocentrado, pelo modelo gerencial, qualificado, ao contrário, como eficiente e voltado para o interesse público. É possível, contudo, questionar essa posição a partir desse mesmo documento.

No Plano Diretor da Reforma do Estado, não há distinção entre, de um lado, a definição ou caracterização desses modelos ou formas de administração - quais sejam, o modelo burocrático e o modelo gerencial - e, de outro lado, o juízo de valor ou julgamento a respeito desses modelos. Ao contrário, essas dimensões estão confundidas e misturadas, com o que se induz o leitor a conclusões precipitadas a respeito das pretendidas qualidades e dos alegados defeitos desses modelos.

Por meio desse procedimento, o leitor é levado, forçado quase a aceitar a tese de que seja indispensável substituir o modelo burocrático pelo gerencial. A fim de demonstrar nossa afirmação, separemos a caracterização e o julgamento, contidos no Plano, acerca de cada um desses dois modelos.

No que toca ao modelo burocrático, são definidos como seus princípios orientadores a "profissionalização", a "idéia de carreira", a "hierarquia funcional", a "impessoalidade", o "formalismo", em síntese, "o poder racional legal”. A esses princípios acrescentam-se as seguintes características: "controles administrativos a priori" e "controles rígidos dos processos”. 
Independentemente dos questionamentos que se façam a respeito dessa caracterização do modelo burocrático - por exemplo, é indispensável que sejam rígidos os controles dos processos, para que se trate de modelo burocrático?; ou ainda: uma hierarquia não-funcional descaracterizaria a natureza burocrática de uma organização? -, é imprescindível não confundir essa caracterização, ou seja, a definição, com a apreciação ou avaliação de modelo administrativo burocrático.

Com efeito, saindo da definição e partindo para a avaliação ou julgamento do modelo, verifica-se, no mesmo Plano Diretor, a afirmação que, nas organizações estatais em que se adota o modelo burocrático, há uma "desconfiança essencial" com relação aos administradores públicos e cidadãos; que o controle ou a garantia do poder do Estado transformam-se em razão de ser do funcionário; que o Estado volta-se para si mesmo, perdendo a noção de sua missão básica - servir à sociedade; e que também, apesar da efetividade do modelo no controle de abusos, ele tem como defeitos a ineficiência, a auto-referência, assim como a incapacidade de voltar-se para os cidadãos "vistos como clientes".

Como dissemos, é preciso separar as características, indicadas no parágrafo mais acima, do julgamento reproduzido no parágrafo anterior. No primeiro caso, há descrição; no segundo, avaliação crítica. Contudo, haveria nexo ou correlação necessária entre uma coisa e outra? A questão a enfrentar é a seguinte: um modelo organizacional marcado por profissionalização, carreira, hierarquia funcional, impessoalidade e "formalismo", em que se controlem (rigidamente?) processos, é intrinsecamente ineficiente, sem sentido de missão, autocentrado e auto-referido, incapaz de voltar-se para o interesse público? Uma coisa leva obrigatoriamente à outra? Tal como redigido, o Plano Diretor toma como certo o que resta ainda ser demonstrado tanto lógica quanto empiricamente ${ }^{7}$.

No que concerne ao modelo gerencial, tido como avanço e, até certo ponto, como rompimento com a administração burocrática, o Plano Diretor o caracteriza como modelo que não rompe com todos os princípios do modelo anterior, o burocrático. De fato, afirma-se que são conservados, "embora flexibilizando", os princípios da "admissão segundo rígidos critérios de mérito", da universalidade em ações ou subsistemas de gestão de pessoal, tais como nos sistemas de remuneração, carreira, avaliação de desempenho e treinamento. A administração gerencial tampouco se diferenciaria da burocrática, no que se refere ao profissionalismo (à rigorosa profissionalização) e à impessoalidade, posto que permaneceriam como princípios válidos na administração gerencial.

Dadas essas equivalências entre os modelos, sustenta-se, de fato, no Plano Diretor, que não se trata de simplesmente descartar o sistema burocrático, ou a administração racional-legal, mas, sim, de identificar tanto os 
aspectos que estão superados quanto aqueles que permanecem válidos.

Obviamente, se os primeiros aspectos devem ser afastados, há de se manterem ou preservarem (aperfeiçoando, eventualmente) os últimos.

É interessante trazer, neste momento, algumas análises contidas em excelente volume relativo à problemática de responsabilização na nova Administração Pública latino-americana, editado pelo Conselho Latino Americano de Desenvolvimento (CLAD). Nessas análises estão também presentes as mesmas ambigüidades entre o modelo burocrático e o gerencial aqui apontadas.

Em uma primeira passagem, retirada da apresentação, sustenta-se a necessidade de abandonar o modelo burocrático. Ali se diz que se impõe

“...reconstruir el aparato del Estado, tornándolo, de un lado más eficiente en realizar sus tareas y más efectivo en enfrentar los desafíos de la goblalización y, de otro lado, asegurando los avances democráticos alcanzados. En el plano de la Administración Pública se hizo evidente que era necesario dar un paso más allá de la Administración Pública burocrática y realizar la reforma gerencial." (CLAD, 2000, p. 9).

Na segunda passagem, retirada das considerações finais, ao contrário, afirma-se serem imprescindíveis os chamados controles burocráticos, ainda que especificamente, ou exclusivamente, para o chamado núcleo estratégico do Estado:

"En el capitulo sobre la resposabilización por medio de los controles clásicos, Groisman y Lerner destacan, en primer lugar, la necesidad de contar con tales instrumentos, inclusive con el cambio de paradigma en la Administración Pública, pues su función de garantizar la probidad y la universalidad de los actos gubernamentales es imprescindible. El control de la corrupción y el funcionamiento de determinadas áreas tales como defensa, seguridad y administración de justicia dependen de los controles clásicos, que no pueden ser substituidos, a riesgo de que se vea afectado el proceso de responsabilización de los gobernantes." (CLAD, 2000, p. 330).

Nosso ponto de vista, todavia, é que, respeitadas as particularidades do núcleo estratégico e dos demais setores do Estado, assim como da administração direta e indireta, os chamados "controles clássicos" permanecem indispensáveis para toda a Administração Pública.

Quanto à definição ou caracterização, o modelo gerencial, todavia, distinguir-se-ia do burocrático pela clara definição de objetivos, pela autonomia dos administradores para atingir os objetivos contratados, pela competição administrada, pela descentralização, ou, melhor, 
desconcentração, e redução dos níveis hierárquicos, pela adoção de formas flexíveis de gestão e pela permeabilidade da organização à participação da sociedade civil.

Principalmente, ao passo que o modelo burocrático baseia-se nos processos, o gerencial concentra-se nos resultados. Esta seria a diferença fundamental, relativa à forma de controle: enquanto no modelo burocrático, a ênfase estaria nos procedimentos, ou nos meios, no gerencial haveria deslocamento para os resultados, ou para os fins; no burocrático, controle a priori; no gerencial, controle a posteriori (dos resultados).

Da mesma maneira como se procedeu com relação ao modelo burocrático, há de se distinguir a caracterização da administração gerencial, separando-a do julgamento de quais sejam as qualidades e os defeitos do modelo. É preciso, aqui também, triar a definição, confrontando-a com juízos de valor.

Conforme o Plano Diretor, ao contrário do modelo burocrático, em que a organização volta-se para si mesma, a administração gerencial estaria explícita e diretamente voltada para o interesse público ou da coletividade, jamais confundido com o interesse do próprio Estado. O conteúdo das políticas públicas não é relegado a segundo nível. O cidadão é visto como cliente e como contribuinte; os resultados da ação estatal são tidos como bons não porque processos estejam seguros e sob controle, mas, sim, porque as necessidades do cidadão-cliente estejam sendo atendidas. $\mathrm{O}$ modelo gerencial, tornado realidade no mundo desenvolvido, em face da adoção de valores e comportamentos modernos, teria promovido o aumento da qualidade e da eficiência dos serviços oferecidos pelo setor público.

Mais uma vez, insistimos, é preciso distinguir a definição da apreciação valorativa: haveria correlação necessária entre uma organização estruturada de acordo com as características do modelo gerencial e a obtenção de resultados eficientes e de qualidade?

Uma primeira questão a enfrentar concerne à alegada necessidade de substituir o controle de processos pelo controle de resultados. Antes de tudo: seria essa efetivamente a melhor leitura do próprio Plano Diretor? Sem dúvida, essa é a leitura predominante. De acordo com essa perspectiva, impõe-se não mais controlar processos para, em vez disso, controlar resultados. Todavia, ao se falar em base, ênfase, concentração, não fica ao menos sugerida a hipótese de que não se trataria de substituir, mas, sim, de somar ambas as formas de controle?

De todo modo, seja lá o que se intentou sugerir no Plano Diretor, há de se reconhecer, antes de tudo, que é falsa a questão a respeito da importância dos resultados. Quem sustentaria que resultados não sejam indispensáveis, irrelevantes? Quem afirmaria serem indiferentes os resultados obtidos pelo administrador público? 
Certamente é possível - até mesmo necessário - reconhecer que, muitas vezes, não se tem atentado para os resultados em nossa Administração Pública, que, em outras tantas oportunidades, não se tem sabido monitorar, dimensionar ou, ainda, medir resultados. Faltam indicadores, falta hábito, falta competência... mas certamente ninguém sustentaria que os resultados não importam.

A questão, portanto, passa a ser: além dos resultados, há de se controlarem também os processos? Há diversas maneiras de sustentar resposta positiva a essa questão. Em primeiro lugar, bons resultados dependem de bons processos. Dificilmente ou, no limite, jamais, por intermédio de maus processos, obtêm-se bons resultados. Moral da história: exatamente pelo fato de os resultados serem relevantes faz-se mister atentar e aprimorar os processos que os geram.

Em segundo lugar, muitas vezes, determinado resultado só é aceitável quando a ele se chega por meio de processos legítimos. Reconhecer esse fato implica negar que procedimentos democráticos impeçam a eficiência. Admite-se obter confissão por meio de tortura? Pode-se contratar funcionário, por eficiente que seja, burlando a norma do concurso, ou qualquer outro nome que se queira dar ao procedimento de escolha, que garanta que a prevalência e comprovação dos princípios de mérito e competência? É aceitável demitir servidor sem justificar e motivar esse desligamento?

Em terceiro lugar, em muitas circunstâncias, os melhores resultados só podem ser determinados por meio de procedimentos formais, ou seja, por meio de processos. Analogicamente, equivale à clássica distinção entre o governo dos homens e o governo das leis. ${ }^{8}$

Por exemplo, qual é a melhor contratação a se fazer, seja de pessoas físicas, seja de pessoas jurídicas? Haveria forma mais correta ou legítima de responder tal questão do que, respectivamente, o concurso público e o processo licitatório?

Como se pode verificar, não se sustenta a alegada distinção entre os modelos burocrático e gerencial, ao menos se compreendida como a substituição do controle dos processos pelo controle dos resultados.

A segunda questão a se enfrentar concerne à referida necessidade de 'flexibilização' dos princípios do modelo burocrático, o que requer, inicialmente, estabelecer o que se toma por flexibilização.

Há duas possibilidades: na primeira, a mudança proposta pelo Plano Diretor consiste na troca ou substituição de um modelo por outro, do burocrático pelo gerencial; nesse caso, trata-se de uma ruptura, sendo esse o significado a se atribuir à idéia de flexibilização.

Na outra, todavia, e tal qual sugerido por Sennet (1996), a flexibilização não corresponde a ruptura, mas, sim, a aperfeiçoamento. Ora, se o modelo gerencial não afasta, mas flexibiliza os princípios do modelo burocrático (profissionalismo, impessoalidade, mérito, universalismo, etc.) 
por que predomina o entendimento de que se impõe ruptura ou abandono desse modelo?

No próprio Plano Diretor, constatam-se três adjetivações da burocracia: menciona-se a burocracia clássica, em que haveria clara e forte noção do interesse público; mais à frente, critica-se a ideologia do formalismo e do rigor técnico da burocracia tradicional; e, logo a seguir, elogiam-se alguns aspectos, como a capacitação permanente, da boa administração burocrática. Se há uma boa burocracia, o modelo a perseguir, dito gerencial, seria ainda o burocrático, cujos princípios estão flexibilizados, logo fortalecidos?

Essa perspectiva, que julgamos estar inscrita no próprio documento Plano Diretor da Reforma do Estado, parece consistir em releitura que rompe fortemente, e para melhor, com a interpretação predominante a respeito da adequada estratégia para a reforma da Administração Pública ${ }^{9}$.

Resta agora aplicar essa reflexão à questão da melhor forma de carreira em nossa Administração Pública, mais especificamente à compatibilidade, ou não, entre o sistema de carreira e o modelo burocrático.

Não é possível, no âmbito deste artigo, discutir a questão com a profundidade desejável. Todavia, impõe-se afirmar claramente a tese de que o modelo burocrático e a carreira pública moderna, ágil e flexível, são perfeitamente compatíveis.

É bem verdade que essa não é a situação vigente na carreira pública. Contudo, por ocasião da Emenda Constitucional n ${ }^{\circ} 19$, perdeu-se excelente oportunidade para corrigir grave equívoco da Constituição Federal de 1988. Como no art. 37, inciso II, da Constituição atual impõe-se que "a investidura em cargo ou emprego público depende de aprovação prévia em concurso público" (na Constituição anterior, de 1969, falava-se em primeira investidura), entende-se - inclusive o Supremo Tribunal Federal (STF) que, ao menos, na administração direta estão proibidos os chamados provimentos derivados ${ }^{10}$. Em outras palavras, salvo se por meio de concurso público, está vedada a mudança de um para outro cargo, até mesmo se houver relação de carreira entre eles. Segundo esse entendimento, não se pode, por exemplo, passar do cargo de escriturário para o de técnico de administração; de técnico de contabilidade para o de contador; ou de auxiliar de jardinagem para o de jardineiro.

Em nosso entender, tal ponto de vista é indevido. Em primeiro lugar, pelo fato de que essa restrição não tem sido estendida para as entidades da administração indireta nas quais vigora o regime celetista, em que se admite que os empregados mudem livremente de "cargo", dispensando-se até que essa mudança submeta-se à lógica de um plano de carreira. Por que esse tratamento tão díspar, se o art. 37 vale para toda a Administração Pública, seja direta ou indireta? Por outro lado, se a própria Constituição Federal, até a promulgação da Emenda $n^{\circ} 19$, obrigava haver plano de carreira na 
administração direta, isso não impunha interpretar de modo mais inteligente, para não dizer "flexível”, a regra do concurso público? Se tanto o concurso público como a carreira são (ou eram) imposições da Constituição Federal, não se havia de buscar uma forma de conciliá-los?

Admitindo-se, todavia, como correto o ponto de vista corroborado pelo STF, aí, sim, haveria uma norma rígida e inflexível na Constituição de 1988. Mas, nesse caso, então, por que não se modificou o art. 37, explicitando, excepcionando, que, por meio de evolução em carreira, é possível mudar de cargo? Não se prevendo a possibilidade dessa forma de provimento "derivado", deixou-se de avançar; e, ao se retirar desse artigo a menção aos planos de careira, retrocedeu-se.

O problema é grave, pois tanto em um modelo "burocrático" quanto em um modelo "gerencial" é indispensável que os trabalhadores tenham perspectivas e mecanismos concretos de crescimento profissional - o que exige evoluir para cargos e funções efetivamente mais complexos e de maior status - como contrapartida de dedicação, produtividade e comprometimento. Como explicar essa lacuna na reforma?

\section{Conclusões}

Afirmamos, neste texto, que a tese relativa à inadequação do modelo burocrático - a qual levaria à necessidade de substituí-lo pelo modelo gerencial - é somente em parte verdadeira.

De um lado, há, efetivamente, que se estabelecerem novos controles à ação dos burocratas, dadas as complexas relações estabelecidas entre estes e os políticos; impõe-se também tornar mais ágeis e flexíveis os processos e os procedimentos da Administração Pública, os quais têm sido muitas vezes, de fato, ineficientes; é ainda indispensável que a Administração Pública atue com foco em resultados, entendidos como a satisfação do interesse dos cidadãos.

De outro, essas exigências não levam a que o modelo burocrático deva ser abandonado. Ao contrário, a preservação e o fortalecimento de princípios burocráticos - legalidade, impessoalidade, universalidade, entre outros - constituem requisito para a ordem republicana e democrática, assim como para a concretização do Estado de Direito. Além disso, a flexibilização de processos e procedimentos não exige abandonar os princípios do modelo. Ao contrário, é tão necessário quanto possível flexibilizar e aperfeiçoar processos por meio de soluções inteligentes e criativas, que, simultaneamente, os tornem mais eficientes e concretizem os princípios burocráticos, evitando que valores fundamentais da democracia sejam sacrificados. Conforme procuramos sustentar, tal se dá, por exemplo, com relação à gestão de pessoal e, em particular, ao sistema de carreiras. 
1 Nunca é demais relembrar que a discussão relativa à reforma do Estado no Brasil dos anos 90, à semelhança do que ocorreu em muitos outros países nos anos 70 e 80, tem a ver com a profunda crise fiscal que os atinge. Assim, a argumentação construída em torno da necessidade de maior eficiência no funcionamento do aparato burocrático estatal associa-se, decisivamente, à implementação de políticas de reformas de cunho liberal, que tomam a redução dos gastos públicos e o corte de pessoal como soluções privilegiadas para aquele problema.

2 Segundo Aberbach, Putnan e Rockman (1981), a burocratização da política e a politização da burocracia implicam também a adoção de estratégia híbrida de atuação: os políticos baseiam sua atuação cada vez mais no argumento técnico e os burocratas reforçam o aspecto político de suas considerações técnicas, seja mediando interesses de clientelas específicas, seja norteando-se pelos sinais emitidos por políticos.

3 Um bom exemplo de que isso é possível são as possibilidades advindas com as novas tecnologias da informação. Elas trouxeram consigo riquíssimo campo de oportunidades para a adoção de mecanismos inovadores, que podem contribuir decisivamente para o aperfeiçoamento do modelo burocrático. De um lado, permitem mudanças substantivas nas formas de operação e controle, corrigindo deformações ou imperfeições, assim como agregando eficiência, agilidade e racionalização aos processos. De outro lado, não obrigam à perda, ao contrário, preservam, podendo até reforçar a realização dos princípios orientadores que devem pautar o aparato administrativo em uma ordem republicana e democrática. Veja o caso das compras efetuadas por via eletrônica, as quais não somente barateiam, agilizam e racionalizam os procedimentos licitatórios - tornando-os mais eficientes - como, ao mesmo tempo, conservam e aperfeiçoam a concretização da publicidade, transparência, impessoalidade e universalidade.

4 "A burocracia moderna funciona da seguinte forma específica: as atividades regulares necessárias aos objetivos da estrutura governada burocraticamente são distribuídas de forma fixa como deveres de ofício; a autoridade (...) se distribui de forma estável, sendo rigorosamente delimitada pelas normas; tomam-se medidas metódicas para a realização regular e contínua desses deveres; somente as pessoas que têm qualificações previstas por um regulamento geral são empregadas" (Weber,1963, p. 229).

5 Eficiência e qualidade, para nós, significam a realização do interesse público. A principal questão a considerar é se há garantia ou, ao menos, maior probabilidade de o interesse público ser atingido por meio de sistema administrativo em que se conceda forte grau de discricionariedade e de liberdade de ação aos agentes públicos.

6 "Formalismo" é a expressão utilizada no Plano Diretor. Não é, todavia, a mais adequada, na medida em que carrega um viés ou juízo de valor negativo, assim como ocorre em expressões, tais como "democratismo", "basismo", etc. Mais correto seria falar em respeito à dimensão formal, às regras ou normas que moldam os procedimentos, e estabelecem direitos e deveres. Sob essa perspectiva, o "formalismo", em vez de negativo, torna-se condição indispensável para instituição e preservação de garantias.

7 Ao contrário do que muitos pretendem, é possível sustentar que a burocracia foi, e ainda é, muitas vezes, condição não somente para moralização, ou controle de abusos, mas igualmente para eficiência organizacional. É o que admite, por exemplo, até mesmo o ex-ministro Bresser Pereira, em Introdução à organização burocrática, texto redigido por ele e Prestes Motta no início da década de 1980. Ali se lê: "A segunda causa da importância que ganharam as burocracias nos tempos que correm deriva da pressão por maior 
eficiência. Essa pressão leva os homens a procurar métodos de administrar os sistemas sociais cada vez mais aperfeiçoados, leva-os a criar um número cada vez maior de burocracias - o tipo de sistema social mais racional e eficiente que até hoje se conhece.

8 Em outras palavras, e também analogicamente, trata-se do reconhecimento da importância da dimensão formal da democracia. Admitir que resultados possam ser obtidos independentemente dos meios que se utilizam levaria a aceitar um governo puramente tecnocrático ou, no limite, até mesmo a concordar com o "rouba mas faz".

9 Segundo a interpretação predominante, tratar-se-ia de substituir o modelo burocrático pelo modelo gerencial. Todavia, há de se considerarem, em vez disso, as seguintes possibilidades: 1) a instituição de modelo híbrido: meio burocrático, meio gerencial; 2) o resgate ou recuperação do modelo burocrático clássico, por meio da eliminação de desvios ou imperfeições; 3) a atualização do próprio modelo burocrático, que se tornaria "burocracia gerencializada".

${ }^{10}$ Provimento derivado consiste em passar servidor de um para outro cargo, sem que seja por meio de concurso público.

\section{Referências bibliográficas}

Aberback; Putnam; Rockman. Bureaucrats and politicians in western democracies. Cambridge: Harvard University Press, 1981.

AzEvedo. Clovis Bueno de. Os servidores públicos e a burocracia. In: Burocracia e reforma do Estado. Fundação K. Adenauer, 2001.

Bobbio, Norberto; Manteuci; Nicola; Pasquino, Gianfranco. Dicionário de política. Brasília: Editora Universidade de Brasília, 1986.

Brasil, Presidência da República. Plano Diretor da Reforma do Estado. Brasília: Câmara da Reforma do Estado/Ministério da Administração e Reforma do Estado, 1995.

Bresser Pereira, Luiz Carlos. A reforma gerencial de 1995. In: Burocracia e reforma do Estado. Fundação K. Adenauer, 2001.

Cohn. G. Introdução. In: Weber, M. Parlamentarismo e governo em uma Alemanha reordenada. Rio de Janeiro: Vozes, 1993.

CLAD. La responsabilización en la Nueva Gestión Pública Latinoamericana. Buenos Aires: CLAD, BID, Eudeba, 2000.

Cunill, N. G. Responsabilización por controle social. In: La responsabilización en la Nueva Gestión Pública Latinoamericana. Buenos Aires: CLAD, BID, Eudeba, 2000.

Etzioni-Halevy, E. Bureaucracy and democracy: a political dilemma. London: Routledge and Kegan Paul, 1983.

LOUREIRO; ABRUCIO. Política e burocracia no presidencialismo brasileiro. In: Revista Brasileira de Ciências Sociais, v. 14, n. 41, out. 1999.

Mainwaring, Scott; Shugart, Matthew. Presidentialism and democracy in Latin America. Cambridge: University Press, 1997.

Nunes, Edson. A gramática política do Brasil. Rio de Janeiro: Zahar, 1997.

PAlermo, V. Como se governa o Brasil? O debate sobre instituições políticas e gestão de governo. In: Revista Brasileira de Ciências Sociais, v. 43, n. 3, 2001. 
ReIs, Eliza Pereira. Política e políticas públicas na transição democrática. In: Revista Brasileira de Ciências Sociais, n. 9, v. 3, Rio de Janeiro, 1989.

SEnNet, R. A corrosão do caráter. Rio de Janeiro: Record, 1999.

WeBER. Economia y sociedad. México: Editora Fondo de Cultura Económica, 1963.

. Ensaios de sociologia. Rio de Janeiro: Editora Zahar, s/d.

. Parlamentarismo e governo em uma Alemanha reordenada. Rio de Janeiro: Vozes, 1993. 


\section{Carreiras públicas em uma ordem democrática: entre os modelos burocrático e gerencial \\ Clovis Bueno de Azevedo e Maria Rita Loureiro}

Refletindo sobre modelo de carreira mais adequado para a Administração Pública nesta era de economia globalizada e de maiores exigências de eficiência e flexibilidade na gestão dos aparatos governamentais, questiona-se aqui a idéia de que o modelo burocrático deva ser substituído pelo modelo gerencial. Considerando essa idéia apenas parcialmente verdadeira, nossa argumentação vai na seguinte direção: como a burocracia é a forma específica de organização do aparato administrativo do Estado de Direito, este modelo não pode ser rejeitado, sob pena de comprometimento desse Estado. Mas ele precisa ser flexibilizado, superando e reduzindo o formalismo excessivo e a rigidez que sua realização histórica possa ter gerado nos diferentes países. Igualmente, deve ser aperfeiçoado em seus mecanismos de controle, até como condição para sua manutenção eficaz nos governos democráticos contemporâneos.

\section{Carreras públicas en un orden democrático: entre los modelos burocrático y gerencial}

Clovis Bueno de Azevedo y Maria Rita Loureiro

Cuando se reflexiona sobre modelo de carrera más adecuado para la Administración Pública en estas épocas de economía globalizada y de mayores exigencias de eficiencia y flexibilidad en la gestión de aparatos del gobierno, se pregunta sobre que la idea de que el modelo burocrático deba ser sustituido por el modelo gerencial. Si consideramos esta idea en parte verdadera, nuestra contestación es que cómo la burocracia es la forma específica de organización del aparato administrativo del Estado de Derecho, no se puede rechazar este modelo, por poder comprometer este Estado. Él necesita volverse flexible para superar y reducir la excesiva formalidad y la rigidez que su historia pueda haber creado en diferentes países. También debe mejorar sus mecanismos de control, incluso como condición para su eficiente manutención en los gobiernos democráticos contemporáneos.

\section{Public careers in a democratic order: between the bureaucratic and managerial models}

Clovis Bueno de Azevedo and Maria Rita Loureiro

When you think of a more appropriate career model for the public administration in an era of global economy with high requirements for efficiency and flexibility in the management of the governmental apparatus you should reconsider the idea the bureaucratic model should be replaced by the managerial model. If we consider this idea partially true, the argumentation takes the following direction: once the bureaucracy is the specific nature of the administrative apparatus organization for the law state, this model cannot be rejected because it can compromise the state itself. The bureaucratic model needs to be not only made more flexible to overcome and reduce the excessive formalism and the rigidity that its historical events maybe caused in different countries but also improved in control mechanisms, even as a condition to its efficient support to contemporary democratic governments.
Revista do

Serviço

Público

Ano 54

Número 1

Jan-Mar 2003

Clovis Bueno de Azevedo e Maria Rita

Loureiro são professores da Escola de Administração de Empresas de São Paulo da Fundação Getúlio Vargas.

Contato: cazevedo@ fgvsp.br mrloureiro@ yahoo.com 